\title{
El TEMA de la IDENTIDAd EN LOS CUentos de Josefina Plá
}

\author{
Jaroslava MAREŠOVÁ \\ Universidad Técnica de Liberec
}

\begin{abstract}
En): The paper deals with short stories written by Josefina Plá and especially with the topic of identity in them. Josefina Plá is one of the most important writers of Paraguay although she was born in Spain. When she came to Paraguay in 1927, she immediately began to write, publish, and play an important part in the culture of the country that would be her home for the rest of her life. Her short stories, written from the 1940s but published mainly in the 1980s, are less known than her dramas and poetry. She classified her short stories into three main groups: short stories about uprooted people, short stories about her environs, and short stories with fantastic elements. In all of these groups, we can find stories dealing with the topic of identity. This topic seems to have had a special importance for the author since it also appears in other texts in which she writes about her life and her literature. The topic of identity can be considered as one of the keys to the interpretation of the work by Josefina Plá.
\end{abstract}

Keywords (En): Josefina Plá; short story; literature of Paraguay; identity; autofiction

Palabras claves (Es): Josefina Plá; cuento; literatura paraguaya; identidad; autoficción

DOI : $10.32725 /$ eer.2021.017

\section{Introducción}

Josefina Plá es considerada como una de las máximas representantes de la literatura paraguaya del siglo XX. Aunque es conocida sobre todo como poeta, dramaturga y ensayista, por sus cuentos la podemos considerar también como renovadora de la prosa paraguaya: en ese sentido, formaría una especie de triángulo con Augusto Roa Bastos y Gabriel Casaccia. Es cierto que la autora se dedicaba menos a la escritura de cuentos y también que éstos son lo menos conocido de su obra. Además, sus cuentos se publicaban con gran retraso respecto al momento de su creación: por ejemplo, el libro La pierna de Severina del año 1983 contiene cuentos escritos en los años 40 y 50 (BORDOLI DOLCI, 1984 : 310). Plá misma decía que su publicación tardía imposibilitó que los cuentos tuvieran un efecto natural y que su salida a la luz ya tenía un valor más bien documental (Plá citada en MATEO DEL PINO, 2000 : 15). La propia autora entendía sus cuentos como el resultado del interés por el mundo circundante e inmediato (a diferencia de su poesía escrita con una perspectiva y un lenguaje mucho más universales) y los clasificó en tres grupos o vertientes: los cuentos del desarraigo, los que hablan del entorno (ella misma empleaba la palabra dintorno) y de sus gentes y los cuentos fantásticos u oníricos (PLÁ, 1984 : 537).

El rasgo más llamativo de sus cuentos es quizás el protagonismo de las mujeres. Las narraciones suelen girar en torno al tema del desamparo y el abandono de las mujeres paraguayas del estrato social más bajo: las protagonistas son muchas veces madres jóvenes con hijos no aceptados, o mujeres mayores abandonadas a su suerte. 
El destino de éstas es, en realidad, la triste imagen del futuro de aquéllas (PÉREZ LÓPEZ, $2003: 31$ ).

Sin embargo, al analizar los cuentos de cerca podemos observar en muchos de ellos dos impulsos o motivaciones más generales, a saber, la voluntad de darles la voz a los que no la tienen y la indagación en el tema de la identidad. En realidad, las tres consideraciones (desamparo de la mujer, carencia de voz del desheredado e identidad) están estrechamente relacionadas. Josefina Plá, por primera vez en la literatura paraguaya, les da el espacio y la oportunidad de hablar a las mujeres (y lo hace también en sus obras de teatro) y este rasgo de sus cuentos ha sido valorado muy positivamente por la crítica. Pero no son exclusivamente las mujeres pobres o del ambiente rural a las que la autora les da la voz, a veces los cuentos toman perspectivas muy sorprendentes: por ejemplo, en «Prometeo» un paralítico reflexiona sobre la sensación de estar distanciado de su propio cuerpo; en «Aborto» el niño en el vientre de su madre piensa en su existencia. Aquéllos, cuya voz no se escucha normalmente, nos hablan desde las páginas de los cuentos de Josefina Plá.

Y son precisamente estos protagonistas poco habituales - los que no tienen la voz - los que la llevan a reflexionar sobre cómo se construye y de qué depende la identidad de una persona. El tema de la identidad tiene evidentemente una estrecha relación con la biografía de la autora: era española de nacimiento, para más señas canaria, pero se integró en el país al que llegara en 1927 de tal manera que terminó por convertirse en una figura clave de la cultura paraguaya. En los prólogos a sus obras se refiere muchas veces a su vida y al cambio radical que para su personalidad y también para su creatividad supuso el cambio de país. En realidad, la pregunta por la identidad se escucha también en su poesía lírica, pero será la prosa el género que le servirá para indagar más acerca de este tema (MATEO DEL PINO, 2002 : s. p.). Este trabajo pretende realizar una reflexión sobre el tema de la identidad en los cuentos de Josefina Plá.

\section{Los cuentos de Josefina Plá y el tema de la identidad}

Si analizamos los cuentos de los tres grupos en los que los dividía la autora, veremos que el tema de la identidad aparece en textos por lo demás muy diferentes entre sí.

En los cuentos del desarraigo nos encontramos con personajes de la colonia, españoles que llegan a la tierra paraguaya más o menos por azar. El más emblemático es el cuento «La mano en la tierra» (escrito en 1952) por el que la autora debió de sentir una cierta predilección ya que lo incluyó en dos colecciones suyas (La mano en la tierra, 1963, y La pierna de Severina, 1983) y también en la colección de cuentos paraguayos Crónicas del Paraguay (1969) (MATEO DEL PINO, 2000 : 32). El protagonista, don Blas de Lemos, un conquistador ficticio del siglo XVI, reflexiona acerca de su vida en su lecho de muerte. En el cuento no faltan referencias a eventos históricos reales que sitúan la trama en el tiempo: «Hubo de acompañar a Ayolas al Chaco. Él, Blas, pudo haber sido encomendero: prefirió ser de los de arma al brazo. Arriba con Irala, abajo con Cabeza de Vaca, de picada en picada y de fundación en fundación». Estamos, pues, en el siglo XVI y el personaje de Plá tiene ciertas características que lo ligan con Cervantes: «Y cuando quedó 
inútil del brazo izquierdo, pasó a manejar la pluma. Había escrito mucho. Memoriales y mensajes, pliegos que iban y venían por caminos duendes [...]» (PLÁ, 1983 : 93). Es como si la autora intentara examinar qué le podía haber pasado a Cervantes si hubiera conseguido el permiso para cruzar el Atlántico.

Con esto ya tocamos el tema de la identidad que está presente en todo el cuento. El protagonista, desarraigado de su patria, se tiene que adaptar a vivir en ese «planeta de color de cobre», su destino cambia y cambia también el destino de los que lo rodean. Josefina Plá hace aquí el recorrido por muchos tópicos del comienzo de la colonia: las relaciones entre hombres blancos y mujeres indias, las esposas y novias abandonadas en España, el nacimiento de los primeros mestizos, el mestizaje cultural, el verdadero nacimiento de un nuevo mundo. La autora nos brinda la posibilidad, que en las crónicas y relaciones coloniales escasea, de entrever los pensamientos y sentimientos de un colono acerca de sus hijos mestizos. El hombre descubre que sus descendientes son más de la tierra que suyos: «Apenas erguidos sobre piernas, recién llegados a la vida en la tierra aquella, ellos sabían de ella infinitas cosas que para él, Blas de Lemos, serían siempre un arcano» (PLÁ, 1983 : 94). Y ello, a pesar de los intentos de hacerles lo más parecidos posible a él mediante la música y la fe:

«Y tú les enseñaste a tocar tu guitarra clara, tan distinta de sus raros instrumentos de ahogado gemir, y ellos aprendieron pronto; pero cuando empezaron a tocar solos, su música no era ya la que tú conocías [...]. Y escuchan atentamente a los hombres de Dios que traen Su Palabra, y reciben contentadamente el bautismo; pero adivinas que cuando le hayan acogido para siempre, ya no será el mismo, porque ellos habrán descubierto que Él puede tener también su rostro, y se lo cambiarán [...].» (PLÁ, 1983 : 94-95).

La guitarra en las manos de los hijos mestizos se convierte en un instrumento distinto de lo que debería ser, Dios en su imaginación tendrá otro rostro. El protagonista observa con sorpresa y cierta molestia que lo que él y los suyos habían traído a la tierra adquiere en ella características diferentes, todo cobra una nueva dimensión. En su perspectiva, la guitarra es superior a los «raros instrumentos» de los nativos, pero el intento de perpetuar su cultura en el nuevo ambiente fracasa rotundamente: la guitarra ya nunca sonará igual.

El protagonista siente que ni siquiera sus hijos, en los que debería reconocerse o «recuperarse», como dice Plá en el cuento, son suyos del todo porque «hay en sus ojos un pasadizo secreto por el cual se te escabullen, y van al encuentro de sus madres en rincones sólo de ellos conocidos» (PLÁ, 1983 : 94). Entre sus hijos hay uno solo que se parece más a él, el hijo menor, Diego. Éste tiene los ojos azules, como el protagonista, que, sin embargo, «parecen un poco extraviados en la color terrígena del rostro» (PLÁ, 1983 : 97). Así que también el intento de perpetuarse en sus hijos fracasa: son tan diferentes que constituyen una realidad inaccesible para él (BELLO, $2001: 332$ ).

Lo que al final de su vida contempla Blas de Lemos es el nacimiento de una nueva cultura, de una nueva identidad, y él había contribuido a ese nacimiento sin proponérselo. Blas de Lemos es «forjador de una nueva raza» a la que, sin embargo, nunca podrá entender (MINARDI, 1998 : 163). Estamos, pues, delante del enigma de la identidad de toda una nación que está naciendo. 
Sin embargo, el tema de la identidad en este cuento tiene una dimensión más personal también. En su agonía, el protagonista se mueve entre los recuerdos lejanos de su patria y las imágenes de su presente. Sabe que la partida de su tierra natal lo había cambiado radicalmente. De la misma manera que no reconoce el canto nuevo de la guitarra, ya no sabe exactamente quién es él mismo: «como cuando en los sueños alguien ha cambiado tu rostro y tu espejo no te reconoce» (PLÁ, 1983 : 94). También acerca de este cuento podríamos decir que la autora lo aprovecha para darnos una perspectiva sorprendente: le da la voz a un viejo conquistador que se está muriendo para que éste exprese el sentimiento de fracaso en un ambiente con el que no puede identificarse y la sensación de enajenación por el rumbo que había tomado su vida. La última frase del cuento es especialmente simbólica: la mano de Blas, tendida hacia el suelo, «parece querer prender la tierra» (PLÁ, 1983 : 98), sin embargo no la alcanza, o sea no puede tocarla, prenderla, hacerla suya. Su deseo de dominar ha fracasado (CоTA, $2018: 24$ ).

Sería fácil establecer una relación entre este cuento y la experiencia de la autora que, como ella misma decía, cruzó el océano como Colón con un sueño a cuestas y a veces hablaba de sí misma como de un Colón minúsculo con falda (PLÁ, 1995 : 25). Plá mencionaba a veces su nostalgia del mar (PLÁ, 1995 : 26) que sentía tal vez igual que su personaje Blas de Lemos. Éste, postrado en la cama y mirando el río bajo su ventana, «con cada camalote que pasa boyando manda una saudade al mar lejano. Al mar de su sed, que no sabe ya si es el mar azulsueño mediterráneo o el mar verdefuria, loco de soledad, que sorteó en su remoto viaje de venida» (PLÁ, 1983 : 89). La autora reconocía que en los cuentos de este tipo había cierta «sublimación», como decía ella, autobiográfica; para ella representaban «un cauce a la angustia lejana de la muchachita desarraigada que fui [...]» (PLÁ, 1984 : 537).

En los cuentos que Plá clasificaba como «del entorno y sus gentes», aparece frecuentemente, asimismo, el tema de la identidad. Estos cuentos, que son los más numerosos, hablan del sufrimiento de las mujeres (en la mayoría de los casos) de los estratos sociales más bajos y guardan ciertos parecidos con los cuentos de Juan Rulfo (aquí hay que tener presente que Plá escribió muchos de ellos en los años 40 y 50). Ambos autores recrean ambientes hostiles y violentos donde reina la injusticia y sus personajes no pueden escapar de su destino y se ven enfrentados con la desilusión y la desesperación. Los cuentos de Juan Rulfo, muy breves, despojados de todo lo innecesario, con personajes que parecen esbozos, son como sus propias fotografías (GONZÁLEZ BOIXO, 2018 : 297); los cuentos de Plá, por su parte, recuerdan a sus obras de teatro, en las cuales las protagonistas se mueven por un mundo-escenario hostil donde las vemos chocarse con otros personajes y fracasar. A la propia Plá le gustaba calificar su cuentística de dramática (Plá citada en MATEO DEL PINO, $2000: 29$ ).

Estos cuentos - narraciones simples, con muchos diálogos en los que se copia el habla de la gente - se centran en la acción y en las consecuencias que ésta tiene para la vida o la muerte de los personajes. Pero, aunque vemos actuar a esos protagonistas, no se dirigen a ninguna solución porque se enfrentan con un ambiente hostil del que no hay ninguna vía de escape (MINARDI, 1998 : 165). Las protagonistas se parecen todas entre sí: son humildes y desprotegidas y a pesar de que tienen nombre propio, en realidad poco importa, porque casi carecen de rasgos 
individualizadores: como si se tratara de un mismo personaje que una y otra vez está obligado a vivir las incontables variaciones del desamparo.

Como ya se ha expuesto, Josefina Plá aprovecha sus textos para darles la voz a los que no la tienen. Entregar la palabra al que carece de ella es un rasgo que cobra un sentido especial precisamente en los cuentos del desamparo. Según algunos estudios, Josefina Plá logró devolver a las mujeres su puesto en la cultura e historia de Paraguay (MATEO DEL PINO, 2002 : s. p.). Los personajes femeninos la fascinaban verdaderamente y no les dedicó solo la mayoría de sus cuentos, sino también otras obras, como, por ejemplo, un ensayo literario: Obra y aporte femeninos en la literatura nacional (1976), así como una serie de entrevistas llamadas En la piel de mujer. Experiencias, (1987) las cuales según Plá no son exactamente periodismo estricto, pero tampoco son fruto de ficción (Plá citada en MATEO DEL PINO, 2000 : 28). Este aspecto de su obra ha sido valorado positivamente por la crítica. La profesora Ángeles MATEO DEL PINO entiende sus cuentos como la revisión de la historia social de la mujer en Paraguay, así como el homenaje personal de la autora a las mujeres paraguayas (2000:28). Francisco PÉREZ MARICEVICH en su prólogo a Crónicas del Paraguay apunta que es Plá quien trae a la literatura paraguaya la denuncia de la situación de muchas mujeres (1969: 12). En ese sentido, los cuentos de Plá se sitúan al lado de los de Gabriel Casaccia y Augusto Roa Bastos. Es con las colecciones El Guajhú (1938) de Casaccia y El trueno entre las hojas (1953) de Roa Bastos con las que la literatura paraguaya da un giro hacia una nueva estética crítica y denunciadora (PÉREZ MARICEVICH, 1969 : 7). El aspecto de denuncia es ciertamente el más visible de los cuentos de Plá. La autora misma explicaba que de sus cuentos «ni uno solo hay que no tenga su protagonista en la realidad», pero que sus protagonistas de «carne y hueso» no sabrían reconocerse en ellos (PLÁ, 1984 : 537 y PLÁ, 1983, Acotaciones temporales : s. p.). Sus cuentos son una acusación al hombre, pero también «una exhortación a la mujer para que aprenda a luchar» (MINARDI, $1998: 170$ ).

Sin embargo, 30 años después de la publicación de su último volumen de cuentos y más de 60 años después de la escritura de muchos, quizá es otro aspecto el que interesa más. Debajo del rasgo denunciador y testimonial sus cuentos tienen un aspecto más universal. Plá decía que a pesar de ser «rebotes de vivencias locales, son universales en su humana raíz» (PLÁ, 1983, Acotaciones temporales : s. p.). La autora lleva a sus personajes a sufrir, a vivir experiencias extrañas y a fracasar, pero antes de aceptar su destino, luchan. Para José Luis APPLEYARD representan un himno no «a la belleza ni a la felicidad, sino a la vida misma, con sus más sombras que luces» (1983, s. p.). Este enfrentamiento del individuo con la vida es quizá lo que más los caracteriza.

Ahora bien, en este grupo de cuentos (del desamparo) podemos encontrar algunos en los que subyace el tema de la identidad. En el cuento «Sisé», la protagonista es una niña india criada como sirvienta en casa del patrón. Éste la había traído tras matar a su madre, a la cual había tomado por accidente por un animal y le había disparado. La niña viene a la casa «cazada» y traída en una red. Más que humana parece ser parte de la naturaleza, arrancada de su seno y transportada por la fuerza. En realidad se trata de un antiguo tópico que aparece en muchas relaciones y crónicas del descubrimiento y la conquista del Nuevo Mundo: el indígena -67 - 
considerado como una «semi-bestia» que forma parte del mundo animal (FERNÁNDEZ HERRERO, 1992 : 87). Plá incluye este motivo también en el ya citado cuento «La mano en tierra» ambientado en la época de la colonia. En éste, don Blas de Lemos desde su lecho de muerte observa a su mujer india, cuyos «movimientos son mínimos y precisos. Hace menos ruido que la brisa en el pasto, afuera» (PLÁ, 1983 : 89). También el patrón cuando aparta a la niña del cuerpo de su madre muerta y la levanta, observa que «piaba como un pájaro» (PlÁ, 1983 : 43). En los pensamientos de estos personajes entrevemos la perspectiva del blanco, del que se siente superior y poderoso: el indígena para él representa una otredad tan radical que sólo sabe identificarlo como parte de la naturaleza.

La niña Sisé al final aprende a vivir en una casa hostil donde la única persona que le habla es la cocinera. Pero incluso ésta no deja de verla como un «animalito» y acepta cuidar de ella porque ya antes había cuidado de un «chanchito». La niña viste ropa que no habría vestido y juega con cosas con las que no habría jugado. El nombre que le deciden poner es un nombre con el que no le habrían llamado.

Precisamente en el nombre se concentra el choque entre los dos mundos y la transformación de la identidad de la niña. Para bautizarla y hacerla más parecida a los otros habitantes de la casa, hay que ponerle un nombre cristiano. Sin embargo, esto es problemático porque la niña no es como los demás: «Fue asunto dilatado hallarle un nombre, porque a nadie se le ocurrió que ese nombre podía ser de todos los días, como Clara o Teresa, [...]» (PLÁ, 1983 : 46). La niña es diferente, y por lo tanto, no puede tener un nombre demasiado corriente. El nombre tiene que indicar su «otredad» a la vez que la tiene que acercar a las personas con las que convive. Por eso, al final le encuentran el nombre cristiano, pero poco común, de Sisenanda o Sisé.

En el cuento se van alternando las dos perspectivas: la de la niña india y la de los habitantes de la casa. Tanto para Sisé, como para los demás personajes, el mundo del otro es siempre extraño, incomprensible. Conforme crecía, Sisé «aprendía apenas a deslizarse, como de prestado, en aquel mundo incomprensible, sólo existía el puente de unas palabras, siempre las mismas, siempre repetidas» (PLÁ, 1983 : 47). La niña no puede llegar a entender el mundo que la rodea, está sola en él. Para los demás, a pesar de estar bautizada y llevar un nombre cristiano, Sisé no deja de ser extraña, más bien parecida a un animal. Cuando se muere la cocinera, la niña «rompió de pronto en un largo alarido, de bestia salvaje; y luego otro, y otro. Un perro, allá en el patio, se sintió solidario, y aulló» (PLÁ, 1983 : 48).

Como no podía acabar de otra manera, Sisé, como tantas otras protagonistas de Plá, es violada por los hombres de la casa y al final muere dando a luz. No deja de ser interesante que la autora, en muchos cuentos de este tipo, problematiza y cuestiona la maternidad. Como nota BELLO, la maternidad es para muchas criaturas de Plá una maldición y tiene consecuencias fatales (2001 : 334). Además, las madres jóvenes son a su vez huérfanas, criadas sin madre, y víctimas de violaciones que no deciden sobre su maternidad y no se identifican con ella. (MINARDI, $1998: 170$ ). El mundo hostil que Plá crea para sus personajes se caracteriza también por la falta de empatía entre los personajes femeninos. La nueva cocinera que llega a la casa del patrón no siente ninguna afinidad con Sisé, en su mirada la niña se degrada todavía más. La cocinera no la ve ni siquiera como un animal: en sus ataques de impaciencia 
la sacude como un «trapo de cocina.» La violencia está siempre ligada al poder, por muy pequeño que éste sea, que una persona puede ejercer sobre otra. Y es importante notar que en los cuentos de Plá, un acto violento lo puede realizar cualquiera, sea hombre, mujer, sea blanco o indio. En este sentido, Plá nunca cae en la simplificación y la esquematización (MINARDI, $1998: 167$ ).

En la historia de Sisé, la violencia y el abuso saltan a la vista, sin embargo, el tema de la identidad está también presente. La protagonista, forzada a cambiar su entorno natural por otro, fracasa en él: es un ser a medio camino entre dos mundos; un ser que ha perdido su casa, familia y lengua y no ha adquirido del todo nada nuevo - vive como de prestado, se expresa siempre con las mismas palabras que le habían enseñado.

Plá explicaba su propio viaje entre dos mundos, mediante el proverbio: «quien ama la flor, ama las hojas de alrededor», y añadía: «el hombre que yo amaba era paraguayo, y yo amé el país cuya identidad parecía trasvasarme a sorbos su voz y su mirada» (PLÁ, 1995 : 26). Según la autora, amar es «ahondar/ raíces a golpe de latido» (PLÁ, Antología poética : 16), integrarse es «tratar de comprender lo que nos rodea, amándolo» (PLÁ, 1984 : 537). Pero sin el amor (en el más ancho sentido de la palabra), el viaje entre dos mundos no es posible. Sisé vive en un entorno del cual el amor parece haber desaparecido del todo, su viaje al mundo del otro fracasa.

Si volvemos ahora a la clasificación que hacía Plá de sus propios cuentos, tenemos que mencionar todavía los cuentos fantásticos u oníricos. Éstos fueron escritos, como explicó ella, partiendo de sueños reales e incluso para ella misma eran difíciles de interpretar: «si yo supiese el exacto significado de esos cuentos, posiblemente no los hubiera escrito» (PLÁ, 1984 : 538). Sin embargo, incluso aquí podemos encontrar, a nivel más fantástico y simbólico, los temas típicos de su cuentística: el enfrentamiento con la vida y la pregunta por la identidad. El tema de la identidad es crucial en el cuento «El rostro y el perro», publicado originalmente en la revista Alcor en 1960 (MATEO DEL PINO, 2000 : 33) y después incluido en los Cuentos completos (1999).

El relato se abre con las reflexiones de una protagonista sin nombre acerca de su propio rostro:

«Estaba cansada de caminar, estaba cansada de todo; pero sobre todo estaba cansada de mi rostro. El rostro que llevaba hacía ya tanto tiempo, no podría decir desde cuándo, sin yo pedirlo: ahora adherido perversamente a mi ser y a mi nombre como la uña a la carne. Y cuán arbitrariamente. Porque yo no lo reconocía, no me reconocía en él, en ese rostro triste y antiguo, que a veces se me antojaba mucho más antiguo que yo; no me reconocía más en él, precisamente ahora cuando todos estaban conformes en que no podía ser de otra.» (PLÁ, 2000 : 279).

La protagonista se siente cansada de su rostro con el que no se identifica, no se reconoce en él. Sin embargo, el rostro está adherido a su persona, forma parte de ella. Lo que más llama la atención en estas primeras líneas del cuento es la idea de una cierta independencia entre la protagonista y el rostro: ella siente como si el rostro fuera más antiguo que ella, como si lo llevara casualmente, como algo no propio. La idea de no reconocerse uno en su propio rostro sorprende porque eso es precisamente lo que solemos considerar como representación de la identidad de una persona. Además, el problema que aquí se nos plantea no es solo el de la pregunta 
de un individuo por su propia identidad, sino también la relación entre éste y su entorno: en la última frase de la cita podemos intuir el conflicto de la protagonista con los que la rodean («cuando todos estaban conformes en que no podía ser de otra»).

Acabamos de ver, páginas atrás, que cuando Blas de Lemos reflexiona acerca de su vida, aparece el mismo motivo, y además expresado con palabras prácticamente idénticas: «como cuando en los sueños alguien ha cambiado tu rostro y tu espejo no te reconoce» (PLÁ, 1983 : 94). Se podría deducir de esto que Plá trabaja con un ritmo semejante al de las variaciones musicales, mencionando ciertos motivos que quedan sin ulterior desarrollo para, posteriormente, retomarlos y recolocarlos en el centro de un nuevo relato y darles entonces un tratamiento más profundo. Pero esto, precisamente, es lo que delata el grado de obsesión de ciertas preguntas reiterativas que forman, con su presencia incesante, la estructura profunda de su obra narrativa breve.

Volviendo a «El rostro y el perro»: la protagonista realiza un paseo nocturno por una ciudad abandonada y silenciosa y siente satisfacción al poder ocultar en las sombras el rostro con el que no se identifica. Su situación aparentemente toma rumbo hacia una solución cuando ve pasar a un extraño «mago» judío (personaje que recuerda a otro similar de Carpentier en «Viaje a la semilla») que sabe cambiarles el rostro a las personas. Un extraño en la calle, cuyo rostro «no tenía facciones que durasen» y «cambiaba de inmediato como una máscara de cera expuesta al fuego», le aconseja ir a ver al mago. La protagonista lo hace y lo deja obrar, pero siente que va a «cometer una traición» (PLÁ, 2000 : 280-281). Una vez que ya dispone del nuevo rostro, desde el espejo le sorpreden los mismos ojos que tenía, que en el nuevo rostro «eran como dos inquilinos solitarios, extraviados». Ante el asombro de la protagonista, el judío responde que los ojos son los mismos y no se pueden cambiar porque tienen que ver desde el principio hasta el fin.

En esta escena podemos notar que la autora repite otra vez, y casi con las mismas palabras, la idea de los ojos «extraviados», ajenos a un rostro, que aparece también en la descripción de Diego, el hijo de don Blas de Lemos, cuyos ojos «parecen un poco extraviados en la color terrígena del rostro» (PLÁ, 1983 : 97). Otra vez vemos lo que acabamos de comentar: el sistema de variaciones. Sin embargo, si allí se trataba de un conflicto de dos rasgos raciales diferentes - los ojos azules en el rostro de color de tierra $-\mathrm{y}$ de la identidad de una persona en cuyas venas circula la sangre mestiza, aquí se trata de una idea más abstracta y universal. Los ojos son, en tanto que representan lo más esencial de una persona, lo que no se puede cambiar y lo que es más propio y acompaña a esa persona desde el principio hasta el final. El rostro, del que la protagonista se siente cansada, es aquello que (creemos) podemos cambiar a lo largo de la vida.

Evidentemente, la solución del problema que ofrece el «mago» es sólo un espejismo. La protagonista no se puede identificar con el rostro nuevo e incluso llega a añorar el antiguo: «Este rostro nuevo no sabía nada de mi vida anterior [...]. Quién sabe si [...] aceptaría como suyas mi soledad y mi orgullo, mi dolor [...]» (PLÁ, 2000 : 281). Cuando la protagonista vuelve a casa del judío para pedir consejo otra vez, éste le responde enigmáticamente que el rostro antiguo la seguirá siempre y la reconocerá. 
Para BELLO este cuento es «prosa surrealista» en la que la autora da paso a una de sus obsesiones: el de la búsqueda de la identidad (2001 : 340). Aunque esta misteriosa historia deja mucho espacio a las interpretaciones del lector, parece claro que la autora explora en ella la inquietud más humana: la de preguntarse quién soy, unas veces reconocerse, otras no, en los propios actos de uno, buscar siempre ese rostro que nos identifica.

\section{Conclusión}

Como ya se ha mencionado antes, los tres cuentos en los que hemos analizado el tema de la identidad, «La mano en la tierra», «Sisé», «El rostro y el perro», pertenecen a tres grupos diferentes de la cuentística de la autora y son muy diferentes entre sí. El cuento situado en la colonia tiene cierto lirismo y está construído con pensamientos íntimos del protagonista y carece de dramatismo. En cambio, el cuento «Sisé» tiene una trama muy clara y el conflicto entre la niña y el ambiente progresivamente cobra fuerza hasta llegar al clímax cuando el patrón abusa de ella. El último cuento, onírico como decía Plá, es un texto construído con elementos fantásticos y deja espacio para la imaginación y la interpretación del lector. El lazo que existe entre ellos es el tema de la identidad. La autora lo aborda desde diferentes ángulos, pero parece ser que sus inquietudes se centran en cómo influye el desplazamiento en la identidad de una persona, cómo una persona puede influir en la identidad del ambiente que la rodea y cómo una persona percibe su propia identidad.

La relación que tienen estas preguntas concretas y el tema de la identidad en general con la vida de Plá es más que evidente. Al leer los prólogos que preparó para diversas obras, propias o ajenas, queda claro que le importaba el asunto de una manera especial. Estos breves textos, siempre emotivos y líricos, son una especie de autoficciones en los que la autora construye una imagen de sí misma para el lector.

La autora confiesa que «nunca olvid[ó] que era canaria» y que «corazón adentro me roía la nostalgia del mar, de la montaña, de los crepúsculos inverosímiles de mi tierra española» (PLÁ, 1995 : 25-26). Con estas frases se acerca mucho a los sentimientos que expresa por boca de su protagonista en el cuento «La mano en la tierra». Una y otra vez habla en estos textos de la aventura que marcó su vida: «me vi abocada, sin buscarlo ni pretenderlo - femenino Colón en microscópica miniatura - a descubrir por mi cuenta [...] otro mundo al otro lado del mar» (PLÁ, 1995 : 25). Es consciente de que su viaje fue hasta cierto punto una repetición de los lejanos viajes del siglo XVI. La autora parece insistir con gusto en esta similitud entre su destino y el destino de los hombres de la conquista. Sin embargo, nunca deja de hacer hincapié en las diferencias: ella es un "Colón femenino» y su mirada se va a fijar en la vida de las mujeres al otro lado del océano. Además, la motivación de su viaje también es diferente: viaja por amor y el amor es lo que le permite integrarse en el nuevo ambiente y adoptar su cultura. En un prólogo, además, Plá confiesa la importancia de la experiencia paraguaya para su escritura y concluye: «es absolutamente seguro que de haber vivido en otro lugar esos cuentos habrían sido diferentes. Es decir, no habrían sido» (PlÁ, 1983, Acotaciones temporales : s. p.). Por eso es lógico que los cuentos, que recogen la huella espiritual de la aventura

$$
-71-
$$


transoceánica y transcultural de la autora, traten precisamente el enigma de la identidad - y ese es un enigma que afecta a la persona y al grupo, que se pregunta por quién soy tanto como por quiénes somos. En su tratamiento de ese tema hay algo que remite a su propia identidad y su experiencia creativa, pero por otra parte, también hay una reflexión de lo que significa Paraguay. La experiencia vital y más profunda de la autora se «sublima» tanto en sus prólogos, como en sus cuentos. Desde esa perspectiva, personal y al mismo tiempo social, como un cruce de líneas que permanece con independencia del tipo de cuento concreto que está ensayando en cada momento, es desde donde hay que estudiar en Plá el tema de la identidad.

\section{BIBLIOGRAFÍA}

\section{Textos}

PLÁ Josefina (s. a.), Antología poética (1927-1977), Asunción, Ediciones Cabildo. PLÁ Josefina (1983), La pierna de Severina, Asunción, El lector.

PlÁ Josefina (1983), Acotaciones temporales, in : PlÁ Josefina. La pierna de Severina, Asunción, El lector, [s. p.].

PLÁ Josefina (1984), Interpretación de mi cuentística, in : BORDOLI DOLCI Ramón Atilio, La problemática del tiempo y la soledad en la obra de Josefina Plá, tesis doctoral, Madrid, Universidad Complutense de Madrid, p. 537-538.

PlÁ Josefina, (1995), Si puede llamarse prólogo, in : MATEO DEL PINO Ángeles (ed.), Latido y tortura. Selección poética de Josefina Plá, Puerto del Rosario, Excmo. Cabildo Insular de Fuerteventura, p. 25-27.

PlÁ Josefina (2000), Sueños para contar. Cuentos para soñar, ed. de Ángeles Mateo del Pino, Puerto del Rosario, Excmo. Cabildo de Fuerteventura, Servicio de Publicaciones.

\section{Estudios}

ApPleYARD José Luis (1983), Breve pórtico, in : PlÁ Josefina, La pierna de Severina, Asunción, El lector, [s. p.].

Bello Javier (2001), A propósito de sueños y cuentos: Josefina Plá, Tebeto: Anuario del Archivo Histórico Insular de Fuerteventura 14, p. 329-342.

BORDOLI DOLCI Ramón Atilio (1984), La problemática del tiempo y la soledad en la obra de Josefina Plá, tesis doctoral, Madrid, Universidad Complutense de Madrid.

Cota Déborah (2018), Josefina Plá e o barro como lugar de arquivo, Revista Travessias 12 (1), p. 21-36.

FERnÁNDEZ HERRERO Beatriz (1992), La utopia de América. Teoría, leyes, experimentos, Barcelona, Anthropos.

GonzÁlez BoIXo José Carlos (2018), Juan Rulfo. Estudios sobre literatura, fotografía y cine, Madrid: Cátedra.

MATEO DEL PINo Ángeles (2000), Introducción, in : Plá Josefina, Sueños para contar. Cuentos para soñar, ed. de Ángeles Mateo del Pino, Puerto del Rosario, Excmo. Cabildo de Fuerteventura, Servicio de Publicaciones, p. 11-34.

MATEO DEL Pino Ángeles (2002), Sellando itinerarios. Género y nación en Josefina Plá, Cyber Humanitatis 22, [s. p.]. 
MATEO DEL PINO Ángeles (2003), ¡Larga jornada sin el pan del beso!... Reelaboración del mito: Rapsodia de Eurídice y Orfeo, de Josefina Plá, in : CAlBARro Juan Luis (ed.), Oficio de mujer. Homenaje a Josefina Plá, La Oliva, Servicio de Publicaciones del Ayuntamiento de La Oliva, p. 71-94.

MINARDI Giovanna (1998), Josefina Plá: una voz a recuperar, Letras femeninas 24 (1-2), p. 157-172.

PÉREZ MARICEVICH Francisco (1969), La narrativa paraguaya de 1940 a la fecha, in : Crónicas del Paraguay, ed. de Josefina Plá, Buenos Aires, Jorge Álvares Editor S. A., p. 7-14.

PÉREZ LÓPEZ María Ángeles (2003), Raíz y altura. La labor teatral, in : CALBARRO Juan Luis (ed.), Oficio de mujer. Homenaje a Josefina Plá, La Oliva, Servicio de Publicaciones del Ayuntamiento de La Oliva, p. 15-37. 
- 74 - 